Sharif University of Technology
Scientia Iranica
SCIENTIA
IRAN I CA
http://scientiairanica.sharif.edu

\title{
Structural control of RC buildings subjected to near-fault ground motions in terms of tuned mass dampers
}

\author{
H. Naderpour*, A. Kiani, and A. Kheyroddin \\ Faculty of Civil Engineering, Semnan University, Semnan, Iran. \\ Received 17 November 2017; received in revised form 30 January 2018; accepted 29 April 2018
}

\section{KEYWORDS \\ Structural control; \\ Tuned mass damper; \\ Passive; \\ Near-fault earthquake.}

\begin{abstract}
To design a proper structure against earthquake in modern systems, control systems are of special importance. An added passive Tuned Mass Damper (TMD) is one of such systems, which will be discussed in this paper. In this regard, the effect of adding this damper to a 10-floor concrete structure under six near-fault earthquakes is investigated. To do this, a code has been written in MATLAB that receives the ground motion record of occurring earthquake as well as the structural specifications such as a matrix of mass, stiffness, and damping as an input. As outputs, a time-history of responses for the top floor, a diagram for the floor displacement, and drift of the structure at the time that the top floor has reached the maximum displacement are presented. In addition, these diagrams are compared both when the added damper is present and absent. It is observed that the added passive control of TMD is highly effective in the reduction of structure response against earthquake, which in turn depends on the properties of the earthquake and, therefore, should be chosen based on the site seismic conditions.
\end{abstract}

(C) 2020 Sharif University of Technology. All rights reserved.

\section{Introduction}

To reduce the problems caused by lateral displacements against dynamic loads such as wind and earthquake, control systems have been allocated special status. While imposing strong dynamic loads such as an earthquake, buildings sustain large displacement after the elastic region and will remain stable only due to their inelastic displacement ability. These inelastic displacements develop local plastic hinges in parts of the structure that lead to ductility increase and energy dissipation. Thus, a large amount of energy is dissipated due to local damages in the lateral-resisting system.

\footnotetext{
*. Corresponding author. Tel.: +98 2333533781 ;

Fax: +982333654121

E-mail address: naderpour@semnan.ac.ir (H. Naderpour)
}

Generally, the structural control systems are divided into four main categories including passive control, active control, semi-active control, and hybrid control. The passive control of structures without imposing external force is used to reduce the structural vibration. In active control, an external force is also used to reduce possible structural vibration. In the semi-active control, parameters of the controller are instantly changed with respect to the amount of the imposed load to improve the performance of the controller; however, a number of passive control systems are combined with active or semi-active control systems to reach better performance in the hybrid control.

The Tuned Mass Damper (TMD) is a passive control device that contains a mass that is attached to the structure by a spring and a damper. Generally, the natural frequencies of the TMD are adjusted toward one of the natural structural frequencies. Hence, the vibration of the main structure is dissipated in 
resonance due to the TMD vibration.

The majority of researchers (including both seismologists and engineers) have analytically and/or experimentally investigated the response of structures under near-fault records or simplified waveforms as representative of actual ground motion pulses [1-5].

TMDs are utilized based on the studies (the results published in 1909) implemented by Frahm on the dynamic vibration absorbers [6]. Bishap and Welbourn discussed the vibration absorbers considering damping in the main structure [7]. In 1956, Den Hartog presented a compiled theory of absorbers in the case of an undamped structure in his book titled "Mechanical Vibrations" in terms of the mathematical analytical equations [8]. In 1967, Falcon et al. studied the optimization of the TMD parameters [9]. In 1981, Randall et al. provided tables concerning parameters of these dampers [10]. Warburton solved the excitations control problem and determined the responses. The application and limitations of these methods lead to the utilization of these formulae for MDOF structures [11]. Villaverde et al. investigated the efficiency of the TMD system during an earthquake. They found that the main reason for using a classic solution was that this method does not optimize values of parameters constantly. They proposed that damper parameters should be adjusted by the main structural mode of the damping ratio [12]. Tsai et al. classically codified this solution for a single-degree-of-freedom system and provided curves for determining the optimized parameters [13]. In 1997, Chang studied the performance of 3 types of the TMDs in controlling the structurally severe seismic shaking. These dampers include TMDs, tuned liquid column dampers, and tuned liquid column impact absorbing damper. Finally, he concluded that the performance of the mass dampers was dependent on a parameter named productivity index [14]. The evaluation of the effect of disturbance in frequency adjustment or other parameters of the TMDs has been studied by researchers in recent years. Rana and Soong evaluated the effects of this kind of disturbances on linear structures [15]. The TMDs can be used in both active and passive control along with Fram works. This concept received much attention, and several studies and researchers evaluated this system to control the resonance load vibrations [16]. In 2002, Lopez Garcia and Soong also studied the distribution of damper's allocation by using the Simplified Sequential Search Algorithm (SSSA). They evaluated the performance of the conventional structures up to 20 stories with the time period of $0.2-0.5$ seconds (they also compared locations of dampers with different distances from the fault determined from various quakes). The aim of the authors was to turn the simplified sequential search algorithm into a simple tool to execute the passive control; by simplifying the execution method, the productivity of the method of controlling seismic waves was weakened [17]. In 2003, Pinkaew et al. evaluated the effect of the TMD in controlling the structure during an earthquake. This study indicated that the TMD was not able to reduce the maximum displacement of the controlled structure after the quake, but could significantly reduce the damage to the structure. Therefore, the application of the TMD to design of the earthquake-resistant structures specifically becomes important [18]. In 2004, Bishap and Striz calculated the minimum required number of passive viscous dampers using the genetic algorithm, which is essential for the structural seismic control [19]. In 2007, Kokil and Shrikhande evaluated the passive viscous dampers and used them for a 3-dimensional 10-story model building in different soil conditions. They came to this conclusion that the influence of the passive dampers decreased as the plan irregularity increased [20]. In 2007, Aydin et al. studied the location of the viscous dampers in a 2-dimensional 10story steel structure model under earthquake. He used the conjugate gradient method of optimization and its different performance. They concluded that the displacement of the last story as an objective performance led to a reduction in story displacement and inter-story drift while increasing the base shear force [21]. In 2009, Ok et al. studied the design of the dual TMDs based on the multi-purpose optimization in an article. In the proposed method, at first, two measurement criteria for the dual TMD systems are identified; then, these operation criteria are used in the form of a vector in the optimized design of the dual TMD. Finally, it is concluded that the proposed method guarantees the optimized design of the effective productivity of the dual TMD in controlling the response of the structure subjected to seismic loads [22]. In 2010, Sgooba and Marano evaluated the optimized design of the tuned mass dampers in order to protect the structure against their response to the earthquake. The problem with this design is solvable by considering 3 meaningful performances:

1. The maximum displacement climax and its standard deviation;

2. The average energy of the protected building and its comparison with an unprotected building;

3. Evaluation of the imposed damage, considering the two previous methods [23].

In 2011, Arfiadi and Hadi optimized the location and features of the tuned mass damper by the genetic algorithm. The optimized location and features received attention in this study. The combination of the location optimization tools and, also, features of the tuned mass damper provide a genetic algorithm. Particularly, while using the real simulation codes of 
the tuned mass dampers under earthquake loads, it was observed that the present methods corresponded to the previous ones and were even advantageous in some cases [24]. In addition, in 2011, Steinbuch optimized the seismic strength of tall buildings by the tuned mass dampers by evolutionary algorithms. In evolutionary optimization, parents' features lead to the production of a new generation with slight differences in features. The generation of children that accomplish the objectives of study more efficiently will become the next parents. The promotion is then studied after the evolution of several generations. Finally, the optimized design is formed toward the height of a tall building, and it is concluded that the effect on the structure is reduced by using this type of dampers [25]. In 2011, Estekanchi and Basim utilized the ETM (Engineering Tolerance Method) and the genetic algorithm to determine the optimized coefficient of the viscous damper to substitute it in 3- and 8-story frames with usual shear forces. They also put it under earthquake in a 35story steel frame with vertical irregularity. The ETM method reduces the number of time analysis essentials and is presented as an alternative design method [26]. Naderpour et al. investigated some control devices, too $[27,28]$. In 2015, Sakr used the mezzanine loads as a tuned mass damper in structure. This technique eliminates the complexity of adding massive loads to control the seismic responses and maintains the initial mass of structure without overload. The effects of using mezzanine loads showed that the proposed method could significantly improve the seismic response against wind and earthquake loads, depending on the ratio of load to the story and the number of stories equipped with the tuned mass damper [29].

Today, a large number of buildings use the tuned mass dampers that include Hancock Tower (Boston, America), City crap Center (New York, America), Sidney Tower (Sidney, Australia), Chipa Tower (Chipa, Japan), Fukuka Tower (Fukuka, Japan), Christal Tower (Ozaka, Japan), The Banda Spatzpoch Cooling Tower (Norenburg, Germany), Canada National Tower (Torento, Canada), and Taipei 101 (Taipei, China).

This study aims to evaluate the effect of the tuned mass damper on the dynamic equations of a structure and compare the displacement and velocity of the system without control. In the case of attaching the tuned mass damper system undergoing 6 near-faults, accelerograms were scaled to $0.35 \mathrm{~g}$. In this article, the tuned mass damper is placed on the roof floor, and the stiffness and damping are considered as an additional story for adding characteristics of dampers to the mass matrix. In many articles, the mass of the tuned mass damper is added to that of the last story. However, the mass of the tuned mass damper is considered as a separate mass in this article. The mass of the tuned mass damper includes applying not only the effect of damper's additional mass on dynamic equations of MATLAB coding, but also the effect of phase difference of the tuned mass damper on the earthquake vibration difference. Given that other articles have not used near-fault earthquake characteristics, the nearfault earthquake accelerograms are used in this article. Finally, by obtaining drift diagrams of the structure with and without control system, the effect of the tuned mass damper on the structural response will be shown.

\section{Problem formulation}

In this part, at first, the dynamic equations of the structure without control system are evaluated; then, the influence of the tuned mass damper on dynamic equations is indicated, and the state-space method is used to solve the differential equations. The mass, stiffness, and damping are the main parameters in solving the dynamic equations of the structure.

Different analysis steps of system vibrations include:

1. The mathematic modeling of the real system;

2. Determination of soil dynamic on system;

3. Solving the dynamic equations;

4. Physical change of the obtained results.

The dynamic equation of a single-degree-of-freedom system is as follows:

$$
m \dot{u}+c \dot{u}+k u=p(t) .
$$

A building is considered as a multiple-degree-offreedom system with respect to the rigidity of its roof. The equations of a single-degree-of-freedom system are generalized to the multiple-degree-of-freedom system, and the above equation is changed to the following differential equation:

$$
[M]\{\ddot{u}\}+[C]\{\dot{u}\}+[K]\{u\}=\{p(t)\},
$$

where $[M],[K]$, and $[C]$ are mass, stiffness, and damping matrices, respectively; $\{u\}$ is the displacement vector of structure; $\{\dot{u}\}$ is the velocity vector; and $\{\ddot{u}\}$ is the acceleration vector of the structure.

The earthquake force is one of the main forces that causes support excitation. The dynamic equation of the motion of a structure under earthquake is as follows:

$$
[M]\{\ddot{u}\}+[C]\{\dot{u}\}+[K]\{u\}=-[M]\{r\} \ddot{u}_{g}(t),
$$

where $\{r\}$ is a $(n * 1)$ vector in which the entry corresponding to degrees of freedom along earthquake acceleration is 1 and in opposite direction of an earthquake is -1 ; other entries are zero, and $\ddot{u}_{g}(t)$ includes earthquake acceleration at different times. 
Thus, dynamic parameters such as $[M],[K],[C]$, and $\ddot{u_{g}}(t)$ are required for the dynamic equation of motion for a structure. Matrices $[M]$ and $[K]$ are obtained by forming the finite element model. The horizontal acceleration $\ddot{u}_{g}(t)$ is also derived from the accelerograms of recorded earthquakes; however, the damping matrix is an unknown value that should be determined by the following method.

Many research studies have been implemented on determining the damping matrix in which there are methods that determine the damping matrix from matrices $[M]$ and $[K]$. In this article, Lord Rayleigh method, in which the damping matrix is obtained by a combination of stiffness and mass matrices known as Rayleigh damping, is used to determine the damping matrix. For this reason, with respect to the following formulae, a code is written in MATLAB that receives the mass and stiffness matrices as input and gives the damping matrix as output:

$$
\begin{aligned}
& {[C]=a_{0}[M]+b_{0}[K],} \\
& \xi_{n}=\frac{a_{0}}{2 w_{n}}+\frac{b_{0} w_{n}}{2}, \\
& \left\{\begin{array}{l}
a_{0} \\
b_{0}
\end{array}\right\}=2 \frac{w_{n} w_{m}}{w_{n}^{2}-w_{m}^{2}}\left[\begin{array}{cc}
w_{n} & -w_{m} \\
-w_{n}^{-1} & w_{m}^{-1}
\end{array}\right]\left\{\begin{array}{c}
\xi_{m} \\
\xi_{n}
\end{array}\right\},
\end{aligned}
$$

where $\xi_{n}$ is the damping ratio of the $n$th mode of the structure, $w_{n}$ is the $n$th frequency, and $w_{m}$ is the frequency of the $m$ th mode of the structure. Since complete information of the ratio of damping in terms of frequency can rarely be found, it is generally assumed that the ratio of damping for the two desired frequencies is equal, e.g., $\xi=\xi_{n}=\xi_{m}$. Therefore, the relations of $a$ and $b$ coefficients are simplified as follows:

$$
\left\{\begin{array}{l}
a_{0} \\
b_{0}
\end{array}\right\}=\frac{2 \xi}{w_{n}+w_{m}}\left\{\begin{array}{c}
w_{n} w_{m} \\
1
\end{array}\right\} .
$$

In this article, the damping ratio of $5 \%$ is considered for all modes, and the first and second modes of the structure are used to determine $a_{0} b_{0}$.

The classical methods, such as Duhamel method, are used for solving the differential equations of the structure, while the state-space method is one of the modern methods for solving the quadratic linear differential equations. A system has several inputs and outputs whose inputs have a complex interaction together. The state-space method works efficiently for this case.

In order to determine the response of the structure in a state space, the state-space variable is considered as follows:

$$
Z=\left\{\begin{array}{c}
\{u\} \\
\{\dot{u}\}
\end{array}\right\} \rightarrow \dot{Z}=\left\{\begin{array}{c}
\{\dot{u}\} \\
\{\ddot{u}\}
\end{array}\right\},
$$

where $Z$ is the state-space variable.
The matrix quadratic differential equation of the structure under earthquake is converted to the statespace form:

$$
\begin{gathered}
{[M]\{u \ddot{(t)}\}+[C]\{u(t)\}+[K]\{u(t)\}} \\
=\{\gamma\} u\{x(t)\}+\{\delta\} \ddot{u} g(t),
\end{gathered}
$$

where $\{\delta\}$ is the influence vector of earthquake, and $\{\gamma\}$ is the control force position vector:

$$
\begin{aligned}
& \{\delta\}=\left[-m_{1},-m_{2}, \cdots,-m_{n}\right]^{T}, \\
& \{\gamma\}=[0, \cdots,-1,1]^{T} .
\end{aligned}
$$

If the structure undergoes the earthquake, all degrees of freedom will experience vibration, while if each of degrees does not experience vibration in their corresponding amount in $\delta$, the vector will be zero. However, all degrees of freedom are subject to an earthquake in this article.

The state-space relation in the linear differential equation is as follows:

$$
\dot{Z}(t)=\left\{\begin{array}{l}
{[A]\{Z\}+[B]\{u\}} \\
{[C]\{Z\}+[D]\{u\}}
\end{array}\right.
$$

where $[A]$ is the system matrix, $[B]$ is the input matrix, $[C]$ is the output matrix, and $[D]$ is the system transfer matrix. Matrices $A, B$, and $C$ are time independent since the mass of the structure is assumed to be constant during the time; the transfer matrix, $D$, is zero since the structure will not vibrate itself, and the external vibration leads to structural movement.

$\left[B_{r}\right]$ is the earthquake input matrix as follows:

$$
\left[B_{r}\right]=\left[\begin{array}{c}
\{0\}_{n * 1} \\
{[m]^{-1}\{\delta\}}
\end{array}\right]_{2 n * 1} .
$$

$\left[B_{u}\right]$ is the active control force input matrix whose value is considered to be zero since the used controller is of passive control; however, it is generally determined by the following relation:

$$
\left[B_{u}\right]=\left[\begin{array}{c}
{[0]_{n * n}} \\
{[m]^{-1}[\gamma]}
\end{array}\right]_{2 n * r}
$$

In writing the equations of the state-space variable:

$$
\dot{Z}=\left\{\begin{array}{l}
\{u\} \\
\{\dot{u}\}
\end{array}\right\}=\left[\begin{array}{ll}
a_{11} & a_{12} \\
a_{21} & a_{22}
\end{array}\right]\left\{\begin{array}{l}
\{u\} \\
\{\dot{u}\}
\end{array}\right\}+\left[\begin{array}{l}
b_{11} \\
b_{22}
\end{array}\right]\{e q\} .
$$

On the other hand, by multiplying $[M]^{-1}$ by the system equation of motion (Eq. (3)) and moving terms, the following relation is obtained:

$$
\{\ddot{u}\}=-[M]^{-1}[C]\{\dot{u}\}-[M]^{-1}[K]\{u\}-\{r\} \ddot{u_{g}}(t) .
$$

By the combination of the mentioned relation and the 
evident relation of $\{\dot{u}\}=I\{\dot{u}\}$,

$$
\dot{Z}=\left[\begin{array}{cc}
0 & I \\
-[M]^{-1}[K] & -[M]^{-1}[C]
\end{array}\right] Z+\left[\begin{array}{c}
0_{n * n} \\
I_{n * n}
\end{array}\right]\{e q\},
$$

where $\{e q\}=-\{r\} \ddot{u}_{g}(t), 0$ is the zero matrix, and $I$ is the identity matrix.

The tuned mass damper reduces the structural vibration against earthquake by changing the structural frequency and removing the structural frequency from the earthquake frequency. This damper is generally located on the roof of the structure.

Some studies have evaluated the effect of adding the mass of the tuned mass damper to that of the story on which the damper is located. However, the mass damper is considered as a separate mass and an additional story in this article.

The tuned mass damper includes 3 parameters: $k_{t m d}, m_{t m d}$, and $c_{t m d}$. The dynamic equations of the structure together with the tuned mass damper are the same as the mentioned equations as follows:

$$
\begin{gathered}
{\left[M_{T}\right]\left\{\ddot{u_{T}}\right\}+\left[C_{T}\right]\left\{\dot{u_{T}}\right\}+\left[K_{T}\right]\left\{u_{T}\right\}} \\
=-\left[M_{T}\right]\left\{r_{T}\right\} \ddot{u_{g}}(t),
\end{gathered}
$$

where $\left[M_{T}\right],\left[K_{T}\right]$, and $\left[C_{T}\right]$ are mass, stiffness, and damping matrices, respectively, incorporated in the tuned mass damper system. In addition, $\left\{r_{T}\right\}$ vector is $(n+1) * 1$ vector with unit entries, and $\left\{Z_{T}\right\}$ vector is $1 *(2 n+2)$ vector that includes the value of displacement and velocity of stories together with the damper.

Generally, the mass of the tuned mass damper is considered as a percentage of the mass of the structure. Moreover, the damper frequency is adjusted near the frequency of the first structural mode (main) given that the tuned mass damper system must be adjusted to the structure. The damping of the tuned mass damper can also be determined by multiplication of the damping ratio by the tuned mass damper critical damping:

$$
\begin{aligned}
& m_{t m d}=m_{0} * m_{\text {building }}, \\
& k_{t m d}=m_{t m d} *\left(\beta_{1} * w_{1}\right)^{2}, \\
& c_{t m d}=2 \xi_{t m d} \sqrt{\left(m_{t m d} * k_{t m d}\right)},
\end{aligned}
$$

where $w_{1}$ is the first structural mode frequency, $\beta_{1}$ is a factor that adjusts the tuned mass damper with a frequency around the frequency of the first mode of the structure. In fact, $m_{0}$, adjustment factor $\beta_{1}$, and damping ratio $\xi_{t m d}$ can be considered as the parameters of the passive control system of the tuned mass damper.

The variation range of the tuned mass damper

\begin{tabular}{|c|c|c|c|}
\hline \multicolumn{3}{|c|}{$\begin{array}{c}\text { The characteristics of the } \\
10 \text { stories concrete structure }\end{array}$} & $\begin{array}{c}\text { Material } \\
\text { properties }\end{array}$ \\
\hline Beam & Column & Story & \multirow{3}{*}{$f_{c}^{\prime}=25 \mathrm{MPa}$} \\
\hline $\mathrm{B} 90 * 50$ & $\mathrm{C} 90 * 90$ & First & \\
\hline $\mathrm{B} 80 * 50$ & $\mathrm{C} 80 * 80$ & Second and third & \\
\hline $\mathrm{B} 70 * 50$ & $\mathrm{C} 70 * 70$ & Fourth, fifth and sixth & \\
\hline $\mathrm{B} 60 * 50$ & $\mathrm{C} 60 * 60$ & Seventh, eighth, ninth & $f_{y}=400 \mathrm{MPa}$ \\
\hline $\mathrm{B} 50 * 50$ & $\mathrm{C} 50 * 50$ & Tenth & \\
\hline
\end{tabular}
control system parameters is provided in Table 1.

In this article, $m_{0}=5 \%, \beta=1$, and $\xi_{\text {tmd }}=15 \%$.
Table 1. The parameters of the tuned mass damper.

\begin{tabular}{cc}
\hline TMD parameters & Variation range \\
\hline$m_{0}$ & $1 \%-5 \%$ \\
$\beta$ & $0.8,0.9,1,1.1$ \\
$\xi_{t m d}$ & {$[0 \%, 1 \%, \cdots, 29 \%, 30 \%]$} \\
\hline
\end{tabular}

Table 2. Characteristics of structure.

\section{Numerical models of a 10-story RC building}

\subsection{General data of the numerical model}

In this article, at first, a 10-story concrete structure with the following plan and characteristics, as shown in Figure 1 and Table 2, respectively, is modeled in ETABS, and the dynamic parameters of the structure are determined in linear and elastic space assuming the rigidity of all roofs and linear behavior of the structural component material.

By considering the concept of "the entries of the stiffness matrix", it is observed that the value of entry $K_{i j}$ is equal to the developed force in $i$ degree of freedom for the unit displacement in $j$ degree of freedom.

Since the roofs are assumed to be rigid, a node is developed in each roof, and all degrees of freedom are fixed to that node; then, support is placed in the node. Then, the unit displacement is applied to the node of roof $i$, and the amount of developed force in support of each roof after running the program is recorded. This
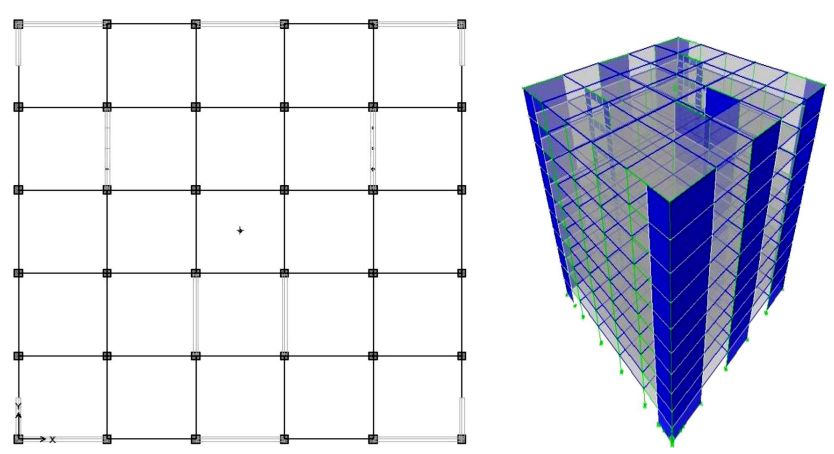

Figure 1. Plan and elevation of the structural models. 


\begin{tabular}{|c|c|c|c|c|c|c|c|c|c|c|}
\hline \multirow{10}{*}{$M=$} & {$[279$} & 0 & 0 & 0 & 0 & 07 & \multirow{10}{*}{$* 10^{3}(\mathrm{~kg})$} & & & \\
\hline & 27 & 275 & 0 & 0 & 0 & 0 & & & & \\
\hline & 0 & 271 & 0 & 0 & 0 & 0 & & & & \\
\hline & 0 & 0 & 264 & 0 & 0 & 0 & & & & \\
\hline & 0 & 0 & 261 & 0 & 0 & 0 & & & & \\
\hline & 0 & 0 & 0 & 254 & 0 & 0 & & & & \\
\hline & 0 & 0 & 0 & 254 & 0 & 0 & & & & \\
\hline & 0 & 0 & 0 & 0 & 254 & 0 & & & & \\
\hline & 0 & 0 & 0 & 0 & 251 & 0 & & & & \\
\hline & 0 & 0 & 0 & 0 & 0 & 216 & & & & \\
\hline \multirow{10}{*}{$K=$} & {$[1.2152$} & -0.5544 & 0 & 0 & 0 & 0 & 0 & 0 & 0 & 0 \\
\hline & -0.5544 & 1.1088 & -0.5544 & 0 & 0 & 0 & 0 & 0 & 0 & 0 \\
\hline & 0 & -0.5544 & 1.0241 & -0.4697 & 0 & 0 & 0 & 0 & 0 & 0 \\
\hline & 0 & 0 & -0.4697 & 0.9393 & -0.4697 & 0 & 0 & 0 & 0 & 0 \\
\hline & 0 & 0 & 0 & -0.4697 & 0.9393 & -0.4697 & 0 & 0 & 0 & 0 \\
\hline & 0 & 0 & 0 & 0 & -0.4697 & 0.8164 & -0.3468 & 0 & 0 & 0 \\
\hline & 0 & 0 & 0 & 0 & 0 & -0.3468 & 0.6935 & -0.3468 & 0 & 0 \\
\hline & 0 & 0 & 0 & 0 & 0 & 0 & -0.3468 & 0.6935 & -0.3468 & 0 \\
\hline & 0 & 0 & 0 & 0 & 0 & 0 & 0 & -0.3468 & 0.6261 & -0.2793 \\
\hline & 0 & 0 & 0 & 0 & 0 & 0 & 0 & 0 & -0.2793 & 0.2793 \\
\hline \multicolumn{11}{|c|}{$* 10^{8}(\mathrm{~N} / \mathrm{m})$} \\
\hline \multirow{10}{*}{$C=$} & 1.5815 & -0.7017 & 0 & 0 & 0 & 0 & 0 & 0 & 0 & 0 \\
\hline & -0.7017 & 1.4462 & -0.7017 & 0 & 0 & 0 & 0 & 0 & 0 & 0 \\
\hline & 0 & -0.7017 & 1.3383 & -0.5945 & 0 & 0 & 0 & 0 & 0 & 0 \\
\hline & 0 & 0 & -0.5945 & 1.2299 & -0.5945 & 0 & 0 & 0 & 0 & 0 \\
\hline & 0 & 0 & 0 & -0.5945 & 1.2299 & -0.5945 & 0 & 0 & 0 & 0 \\
\hline & 0 & 0 & 0 & 0 & -0.5945 & 1.0728 & -0.4390 & 0 & 0 & 0 \\
\hline & 0 & 0 & 0 & 0 & 0 & -0.4390 & 0.9172 & -0.4390 & 0 & 0 \\
\hline & 0 & 0 & 0 & 0 & 0 & 0 & -0.4390 & 0.9172 & -0.4390 & 0 \\
\hline & 0 & 0 & 0 & 0 & 0 & 0 & 0 & -0.4390 & 0.8315 & -0.3535 \\
\hline & 0 & 0 & 0 & 0 & 0 & 0 & 0 & 0 & -0.3535 & 0.3870 \\
\hline
\end{tabular}

Box I

operation is implemented for each roof accordingly; finally, the obtained values are inserted into the stiffness matrix of the structure. The lamp matrix is determined with respect to the ability of lamping mass in the roof in ETABS software. Then, the Rayleigh method, for which a code is written in MATLAB, is used to determine the damping matrix. The obtained mass, stiffness, and damping matrix are presented in Box I.

After obtaining the mass and stiffness matrices, the values of mass and stiffness of the tuned mass damper are determined through Eqs. (19) and (20) and are added to the mass and stiffness matrices of the structure as a separate story, and the damping of the tuned mass damper is then determined according to Eq. (21).

\subsection{Earthquake loading}

The accelerogram data of near-fault earthquakes of Chi (Taiwan), Imperial Valley, Kobe (Japan), Kocaeli (Turkey), Loma Prieta (San Francisco), and Northridge (California) are used to show the effect of earthquake, since the performance of the tuned mass damper is better indicated in near-fault earthquakes, and they are less evaluated in other studies.

All earthquake accelerograms are scaled to $0.35 \mathrm{~g}$ by Seismosignal software; then, a code is written by MATLAB software including all the aforesaid formulae in which the quadratic differential equations of the structure are solved through the state-space method and are considered as the inputs of the mass, stiffness, and damping matrix of a structure without control 

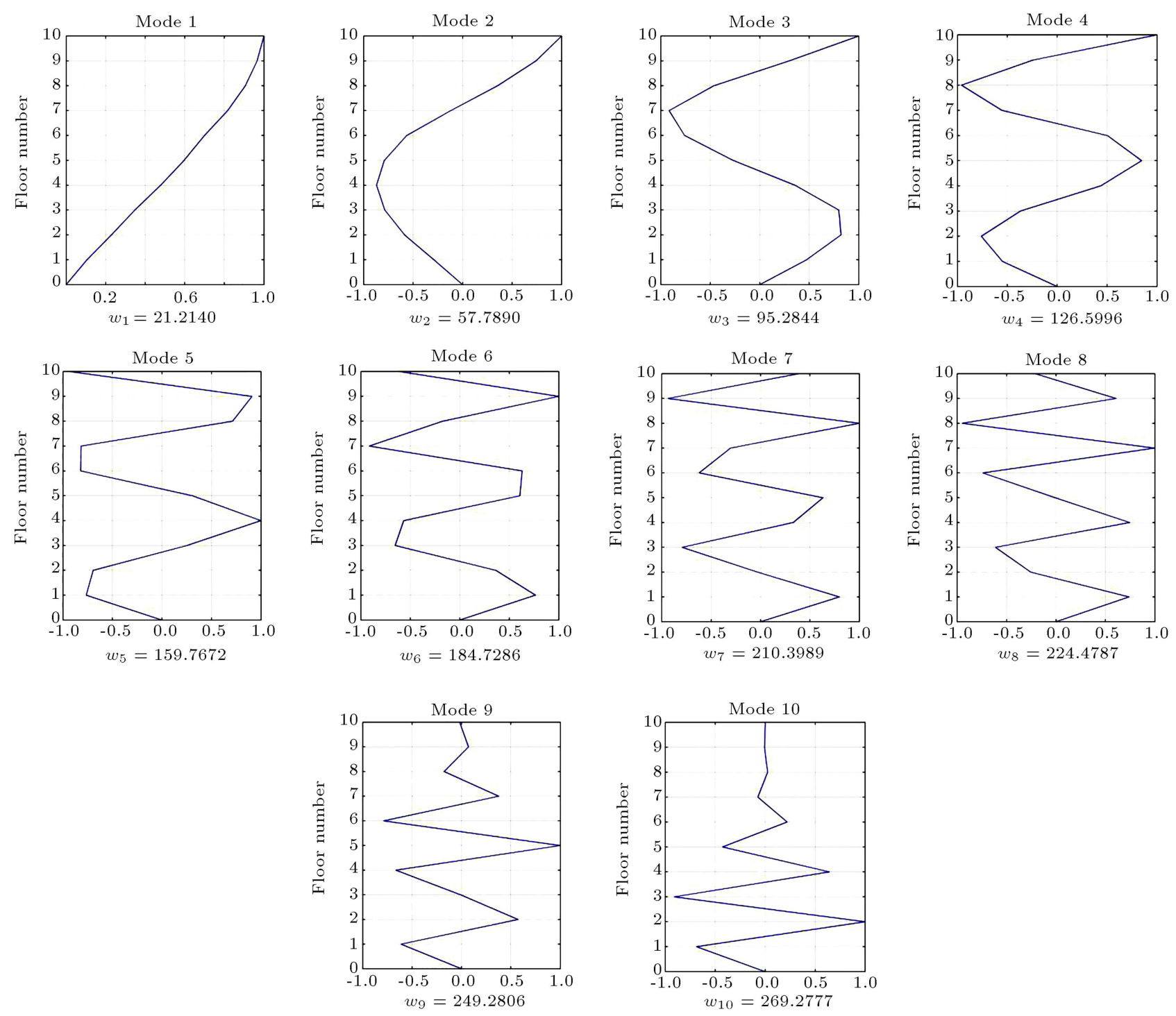

Figure 2. Modal shapes of the 10-story concrete structure.

Table 3. Characteristics of utilized records.

\begin{tabular}{lcccccc}
\hline \multicolumn{1}{c}{ Record } & $\begin{array}{c}\text { Year of } \\
\text { occurrence }\end{array}$ & $\boldsymbol{M}_{\boldsymbol{s}}$ & Station & PGA (g) & PGV $\left(\frac{\mathbf{c m}}{\mathbf{s}}\right)$ & PGD (cm) \\
\hline Chi & 1999 & 7.62 & TCU068 & $0.072 \mathrm{~g}$ & 21.813 & 13.548 \\
Kocaeli & 1999 & 7.4 & Izmit & $0.322 \mathrm{~g}$ & 143.383 & 185.795 \\
Northridge & 1994 & 6.69 & Jansen filter plant & $0.932 \mathrm{~g}$ & 152.747 & 69.613 \\
Loma Prieta & 1989 & 7.1 & Gilory array & $0.966 \mathrm{~g}$ & 217.100 & 264.854 \\
Imperial-Valley & 1979 & 6.9 & Calipatria & $0.270 \mathrm{~g}$ & 24.785 & 9.203 \\
\hline
\end{tabular}

system and the mass, stiffness, and damping matrix of a structure with the tuned mass damper. In addition, the data of accelerogram of the near-fault earthquakes are received, and the modal shapes of structure, the diagram of the accelerogram of the imposed earthquakes, the time history of displacement and velocity of the last story of structure without control and with the tuned mass damper control, the story displacement diagram of the structure with and without control system once the last story experiences the maximum displacement are presented. These outputs are further discussed.

The modal shapes of the modeled structure are shown in Figure 2.

The accelerogram diagrams of the imposed earthquakes are provided in Figure 3 and Table 3.

\subsection{Results of numerical analysis}

The diagram of comparing the structural displacement 


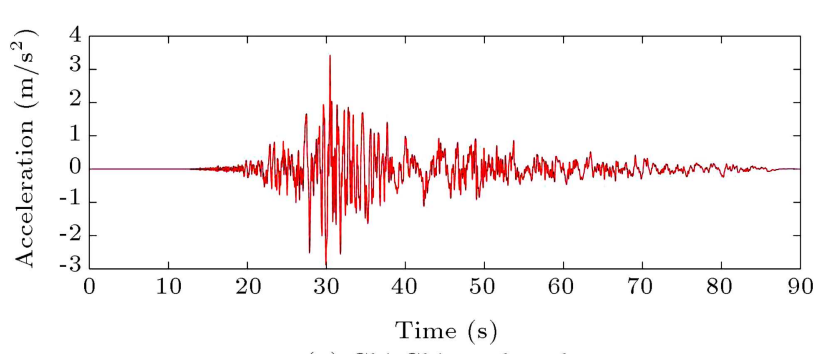

(a) Chi Chi earthquake

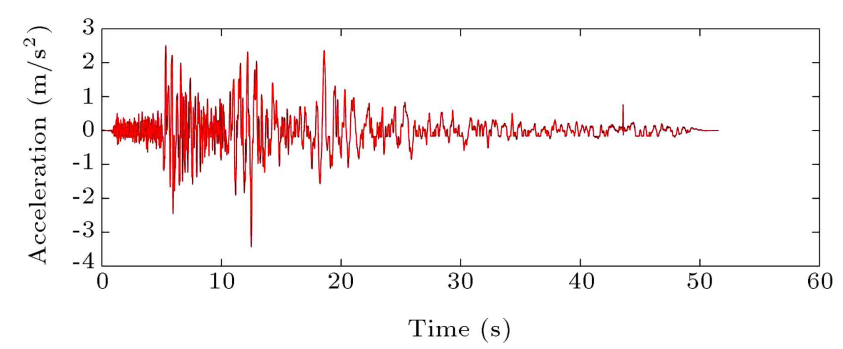

(b) Imperial Valley earthquake

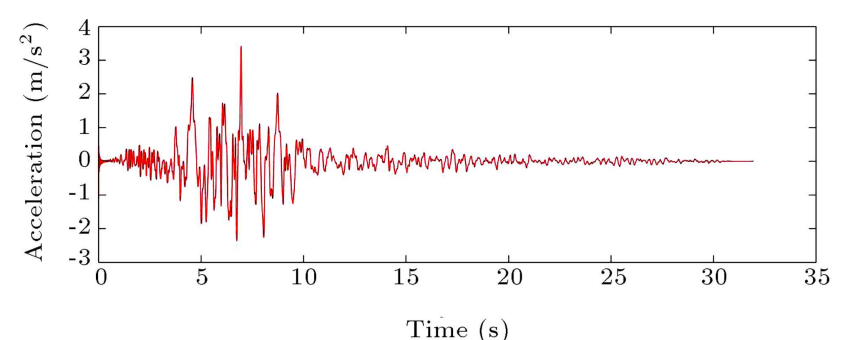

(c) Kobe earthquake

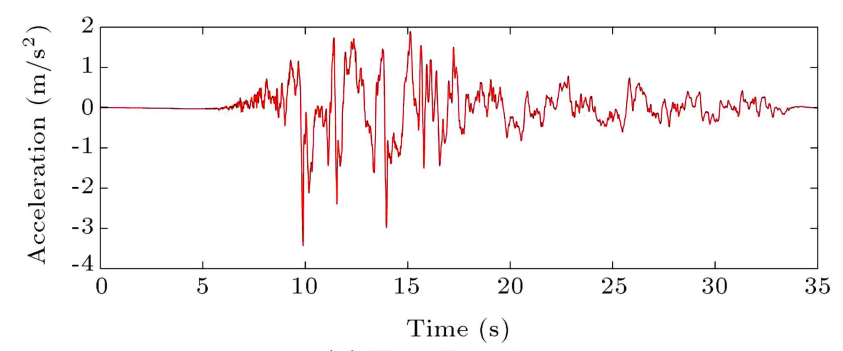

(d) Kocaeli earthquake

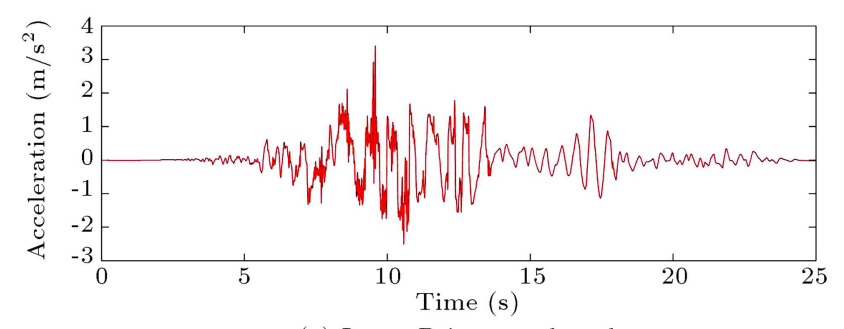

(e) Loma Prieta earthquake

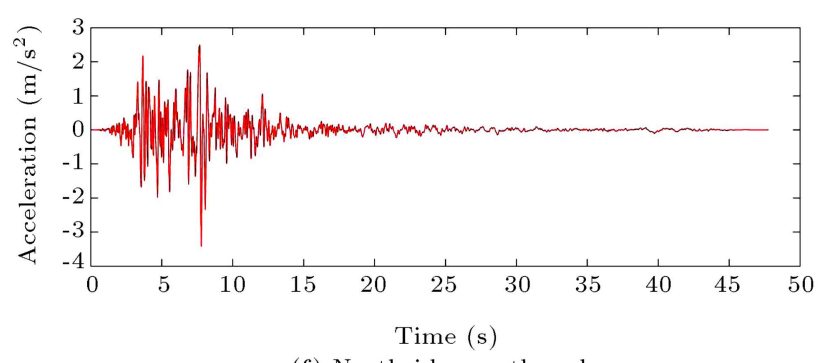

(f) Northridge earthquake

Figure 3. The time-history diagram of $X$ earthquake. time history under the mentioned earthquake accelerograms without control system and with the tuned mass damper control system is presented in Figure 4.

The diagram of comparing time history of the last story velocity under accelerograms of the mentioned earthquake without control system and with the tuned mass damper control system is shown in Figure 5.

\subsection{Discussion of results}

According to the above diagrams, the tuned mass damper reduces the maximum displacement of the last story of the structure in Chi, Imperial Valley, Kocaeli, Loma Prieta, and Northridge earthquakes to $27 \%, 28 \%$, $20 \%, 39 \%$, and $36 \%$, respectively, while it increases the maximum displacement under Kobe earthquake to $20 \%$, which indicates the high dependency of the tuned mass damper on the characteristics of the imposed earthquake.

The displacement-story diagrams for different earthquakes imposed on the structure without control system and with the tuned mass damper once the last story experiences the maximum displacement are provided in Figure 6.

The relative displacement diagrams of the structure without control system and with the tuned mass damper control system once the last story of the structure experiences the maximum displacement are provided in Figure 7.

As can be seen in relative displacement diagrams of the structure, the tuned mass damper reduces the maximum displacement of the structure in Chi, Imperial Valley, Kocaeli, Loma Prieta, and Northridge earthquakes to $35 \%, 34 \%, 27 \%, 40 \%$, and $35 \%$, respectively, while it increases the maximum displacement of the structure in Kobe earthquake to $10 \%$.

\section{Conclusion}

The effect of using the tuned mass damper (passive control) on the structural response under the nearfault accelerograms was evaluated in this study, and the obtained results included:

(a) The comparison between the diagrams of timehistory displacement and velocity of the last story without control system and with control system;

(b) The comparison of diagrams of displacement-story and the relative displacement of stories without control and with the control system.

The use of the tuned mass damper in the structure can significantly influence the control of the structure and reduce the response of the structure against earthquake. The use of the tuned mass damper can be an efficient approach to controlling the structures in Iran with respect to the prevalent use of this control system around the world. The results indicated that 


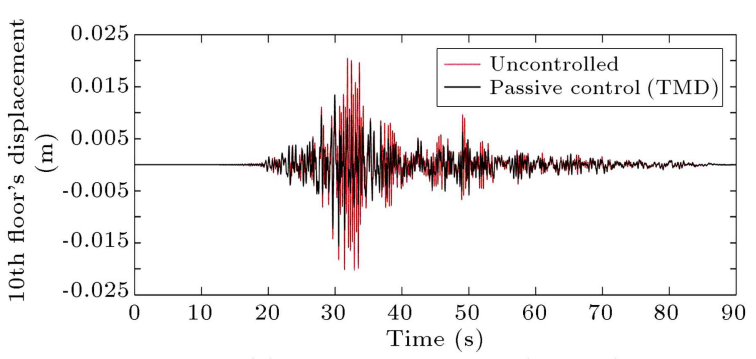

(a) Chi Chi earthquake (Taiwan)

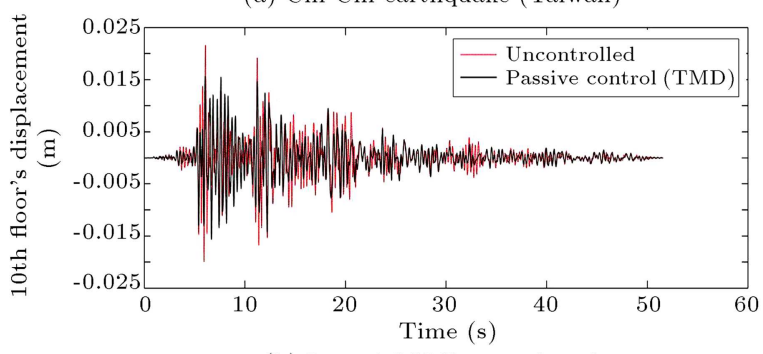

(b) Imperial Valley earthquake

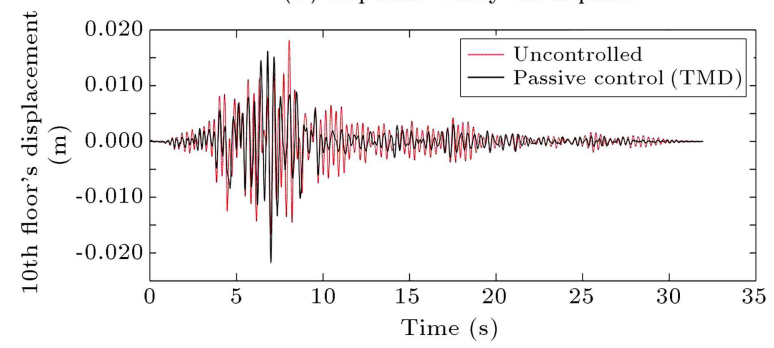

(c) Kobe earthquake (Japan)

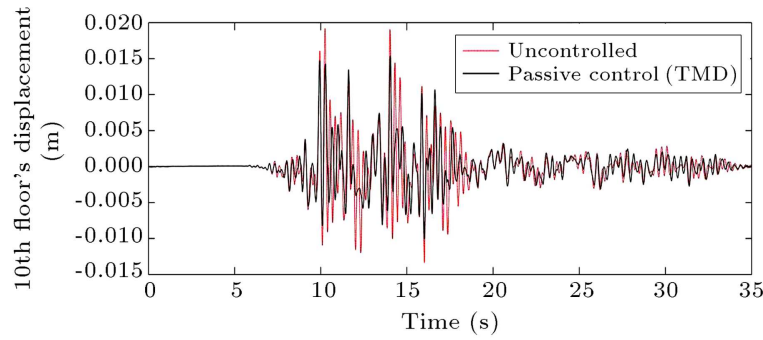

(d) Kocaeli earthquake (Turkey)

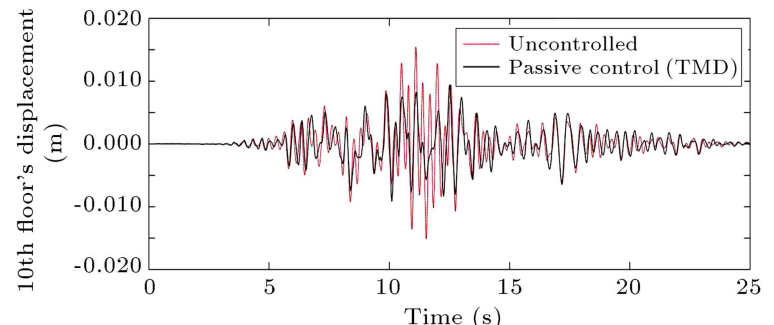

(e) Loma Prieta earthquake (San Francisco)

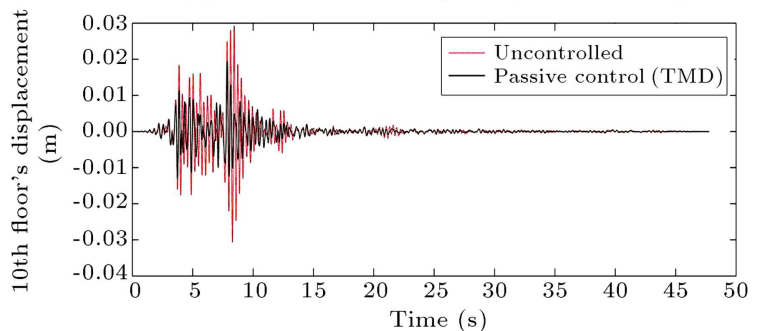

(f) Northridge earthquake (California)

Figure 4. The displacement time history diagram of the structure without control system and with the tuned mass damper under $X$ earthquake.

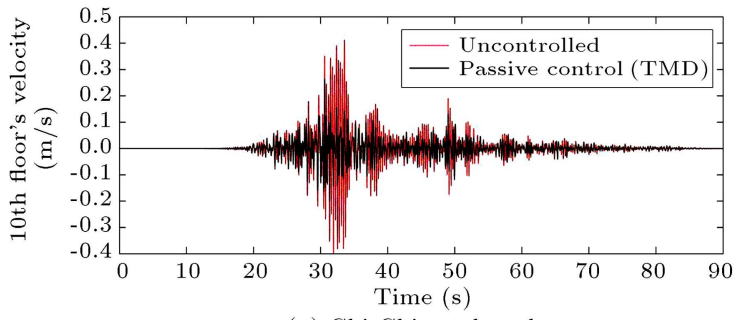

(a) Chi Chi earthquake

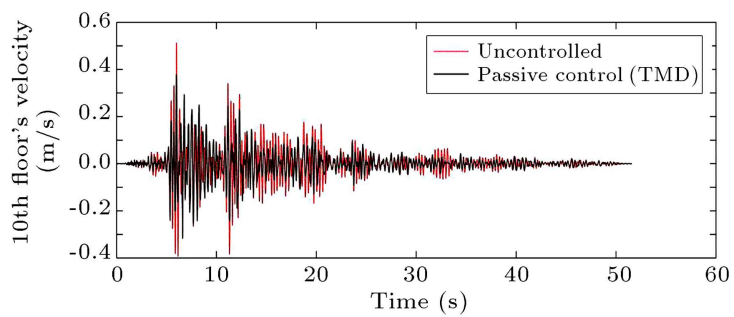

(b) Imperial Valley earthquake

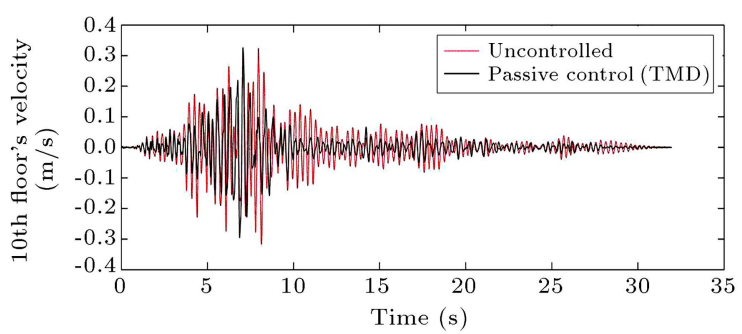

(c) Kobe earthquake (Japan)

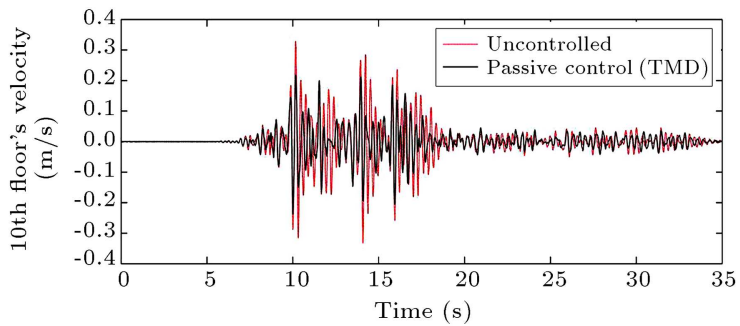

(d) Kocaeli earthquake (Turkey)

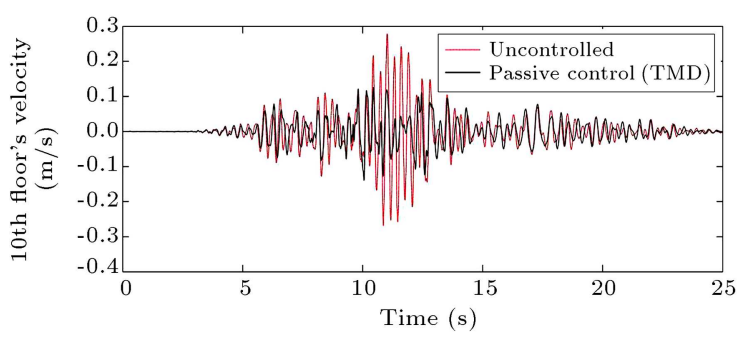

(e) Loma Prieta earthquake (San Francisco)

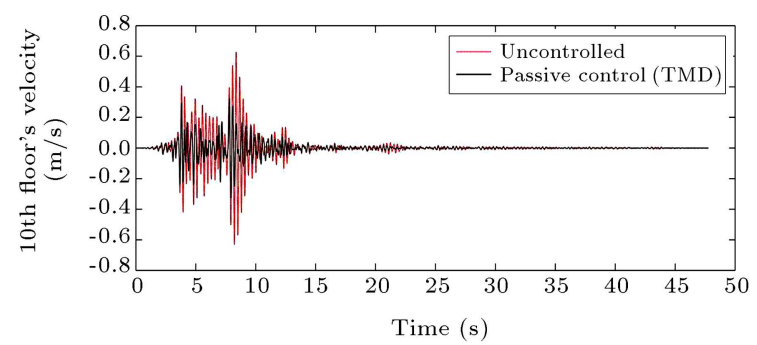

(f) Northridge earthquake (California)

Figure 5. The time history of velocity of the structure without control and with the tuned mass damper under $X$ earthquake. 


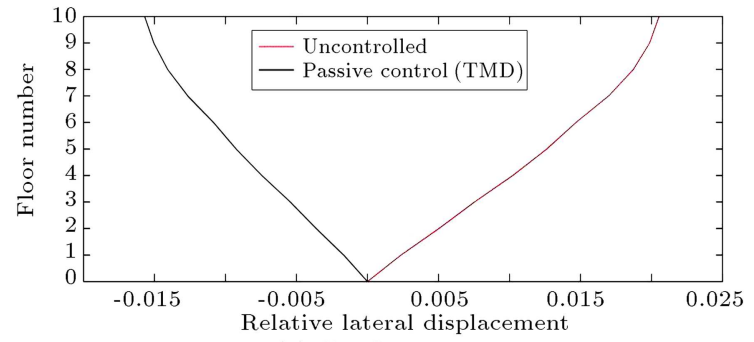

(a) Chi Chi earthquake

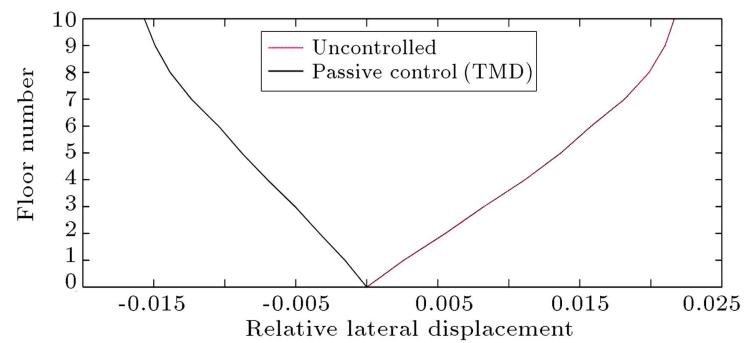

(b) Imperial Valley earthquake

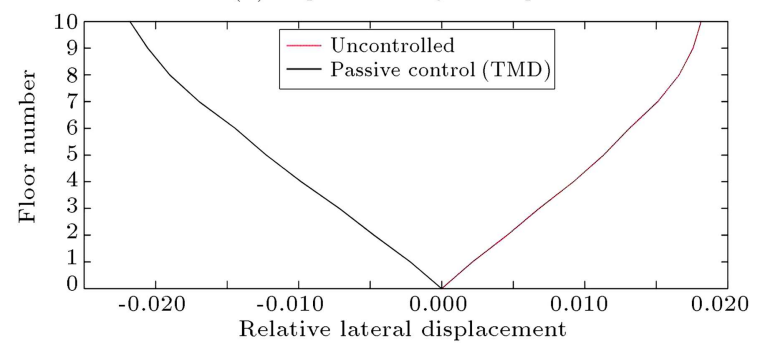

(c) Kobe Valley earthquake

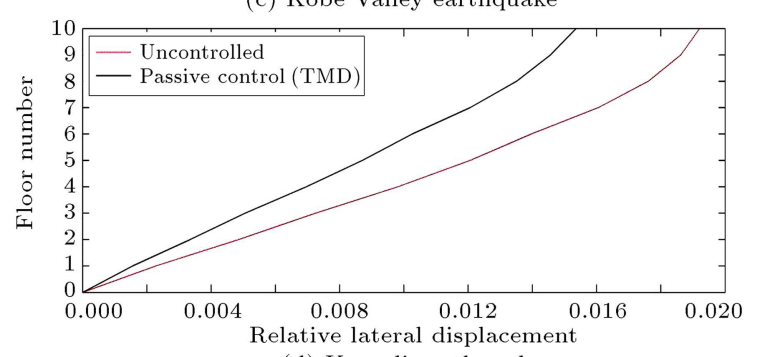

(d) Kocaeli earthquake

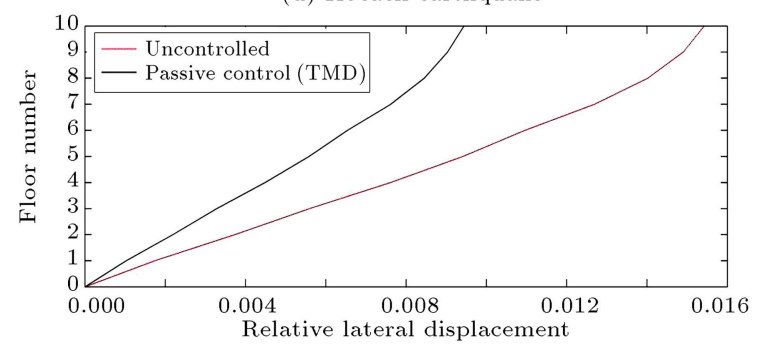

Relative lateral displacement

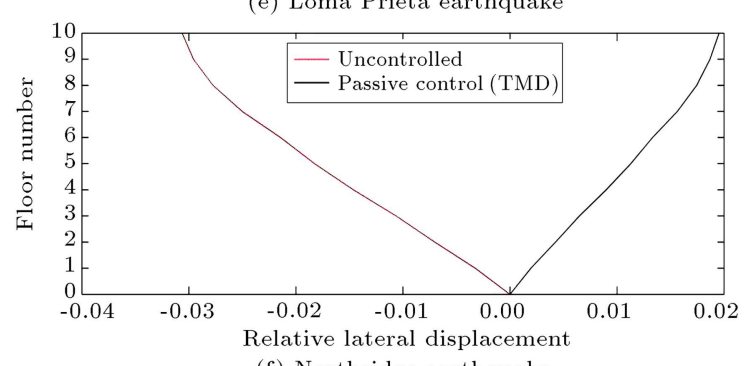

(f) Northridge earthquake

Figure 6. The story displacement diagrams of the structure without control system and with the tuned mass damper control system under $X$ earthquake.

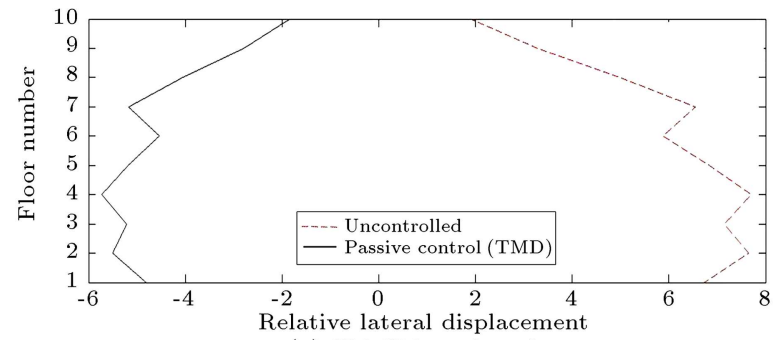

(a) Chi Chi earthquake

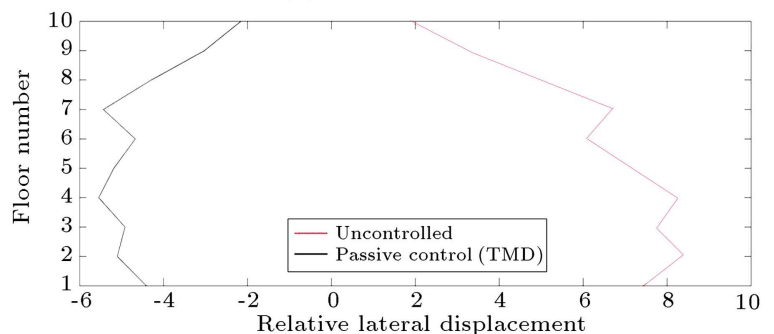

(b) Imperial Valley earthquake

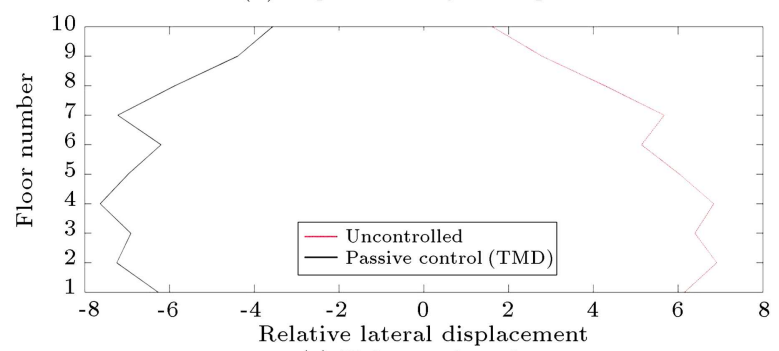

(c) Kobe earthquake

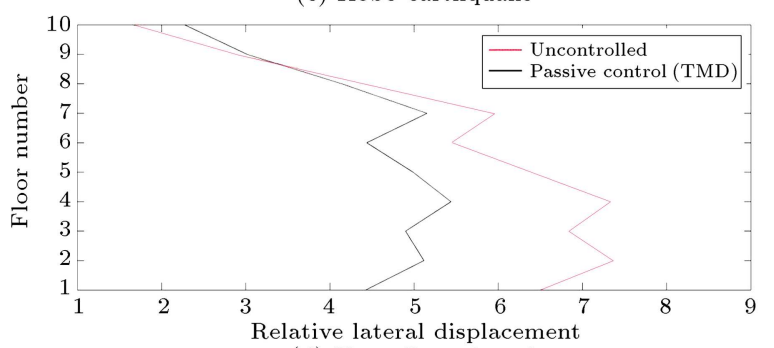

(d) Kocaeli earthquake

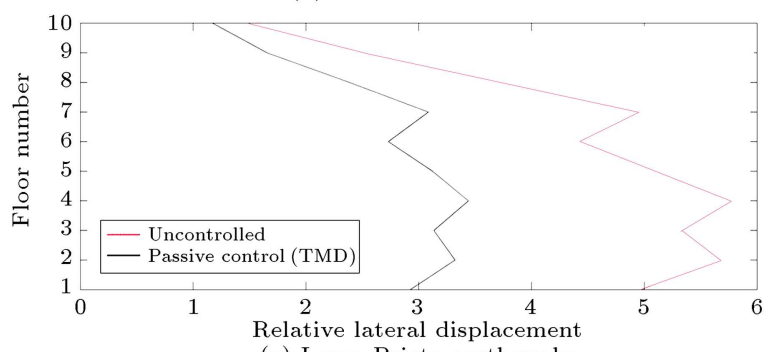

(e) Loma Prieta earthquake

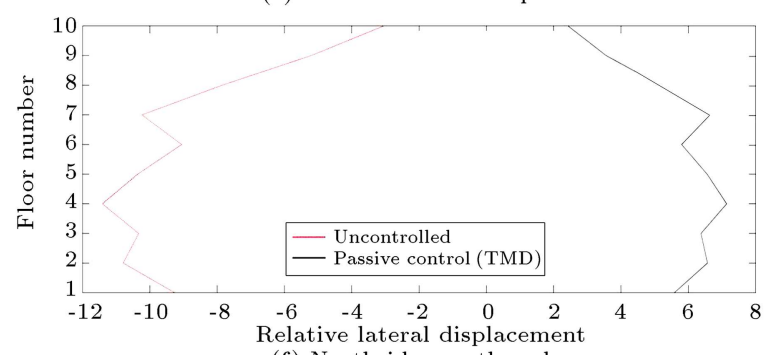

(f) Northridge earthquake

Figure 7. The diagram of relative displacement of stories in the structure without control system and with the tuned mass damper control system under $X$ earthquake. 
tuned mass dampers would considerably reduce the maximum displacement of structures. It should be noted that the mass of tuned mass damper increased in a tall structure, which needs a large space for vibration. Therefore, executive issues should be considered. In order to solve this problem, a number of tuned mass dampers were used instead of a single damper with a large mass. The location of dampers is significantly important, and different optimization methods were used to identify the optimized location of dampers. As was observed, the performance of the tuned mass damper was highly dependent on the characteristics of the imposed earthquake. In fact, the control system received the input earthquake characteristics (accelerogram) and, also, characteristics of the structure (the mass, stiffness, and damping matrices) as input. The characteristics of these dampers should be selected based on seismicity conditions of the region.

\section{References}

1. Hoseini Vaez, S.R., Sharbatdar, M.K., Ghodrati Amiri, G., Naderpour, H., and Kheyroddin, A. "Dominant pulse simulation of near-fault ground motions", Earthquake Engineering and Engineering Vibration, 12, pp. 267-278 (2013). DOI: 10.1007/s11803-013-0170-4

2. Barros, R.C., Naderpour, H., Khatami, S.M., and Mortezaei, A. "Influence of seismic pounding on RC buildings with and without base isolation system subject to near-fault ground motions", Journal of Rehabilitation in Civil Engineering, 1, pp. 39-52 (2013). DOI: $10.22075 /$ jrce. 2013.4

3. Khademi, F., Akbari, M., Jamal, S.M., and Nikoo, M. "Multiple linear regression, artificial neural network, and fuzzy logic prediction of 28 days compressive strength of concrete", Frontiers of Structural and Civil Engineering, 11, pp. 90-99 (2017). DOI: 10.1007/s11709-016-0363-9

4. Kheyroddin, A., Hoseini Vaez, S.R., and Naderpour, H. "Numerical analysis of slab-column connections strengthened with carbon fiber reinforced polymers", Journal of Applied Sciences, 8(3), pp. 420-431 (2008).

5. Sharbatdar, M.K., Hoseini Vaez, S.R., Amiri, G.G., and Naderpour, H. "Seismic response of base-isolated structures with LRB and FPS under near fault ground motions", Procedia Engineering, 14, pp. 3245-3251 (2011). DOI: 10.1016/j.proeng.2011.07.410

6. Frahm, H. "Device for damping vibrations of bodies", U.S. Patent 989958, Issued April 18 (1911).

7. Bishop, R.E.D. and Welbourn, D.B. "The problem of the dynamic vibration absorber", Engineering, London, 174, p. 769 (1952).

8. Den Hartog, J.P. Mechanical Vibrations, Courier Corporation (1985).
9. Falcon, K.C., Stone, B.J., Simcock, W.D., and Andrew, C. "Optimization of vibration absorbers: a graphical method for use on idealized systems with restricted damping”, Journal of Mechanical Engineering Science, 9, pp. 374-381 (1967).

10. Randall, S.E., Halsted, D.M. III, and Taylor, D.L. "Optimum vibration absorbers for linear damped systems", Journal of Mechanical Design, 103, pp. 908913 (1981).

11. Warburton, G.B. "Optimum absorber parameters for various combinations of response and excitation parameters", Earthquake Engineering \& Structural Dynamics, 10, pp. 381-401 (1982). DOI: 10.1002 /eqe.4290100304

12. Villaverde, A., Benito, A., Viaplana, E., and Cubarsi, R. "Fine regulation of cI857-controlled gene expression in continuous culture of recombinant Escherichia coli by temperature", Applied and Environmental Microbiology, 59, pp. 3485-3487 (1993).

13. Tsai, L.H., Takahashi, T., Caviness, V.S., and Harlow, E. "Activity and expression pattern of cyclindependent kinase 5 in the embryonic mouse nervous system", Development, 119, pp. 1029-1040 (1993).

14. Chang, C.C. "Mass dampers and their optimal designs for building vibration control", Engineering Structures, 21, pp. 454-463 (1999). DOI: https://doi.org/10.1016/S0141-0296(97)00213-7

15. Rana, R. and Soong, T.T. "Parametric study and simplified design of tuned mass dampers", Engineering Structures, 20, pp. 193-204 (1998). DOI: http://dx.doi.org/10.1016/S0141-0296(97)00078-3

16. Singh, M.P., Singh, S., and Moreschi, L.M. "Tuned mass dampers for response control of torsional buildings", Earthquake Engineering \& Structural Dynamics, 31, pp. 749-769 (2002). DOI: 10.1002/eqe.119

17. Lopez Garcia, D. and Soong, T.T. "Efficiency of a simple approach to damper allocation in MDOF structures", Journal of Structural Control, 9, pp. 1930 (2002). DOI: $10.1002 /$ stc. 3

18. Pinkaew, T., Lukkunaprasit, P., and Chatupote, P. "Seismic effectiveness of tuned mass dampers for damage reduction of structures", Engineering Structures, 25, pp. 39-46 (2003). DOI: 10.1016/S01410296(02)00115-3

19. Bishop, J.A. and Striz, A.G. "On using genetic algorithms for optimum damper placement in space trusses", Structural and Multidisciplinary Optimization, 28, pp. 136-145 (2004). DOI: 10.1007/s00158004-0441-9

20. Kokil, A.S. and Shrikhande, M. "Optimal placement of supplemental dampers in seismic design of structures", 
Journal of Seismology and Earthquake Engineering, $\mathbf{9}$, p. 125 (2007).

21. Aydin, E., Boduroglu, M.H., and Guney, D. "Optimal damper distribution for seismic rehabilitation of planar building structures", Engineering Structures, 29, pp. 176-185 (2007). DOI: 10.1016/j.engstruct.2006.04.016

22. Ok, S.-Y., Song, J., and Park, K.-S. "Development of optimal design formula for bi-tuned mass dampers using multi-objective optimization", Journal of Sound and Vibration, 322, pp. 60-77 (2009). DOI: 10.1016/j.jsv.2008.11.023

23. Sgobba, S. and Marano, G.C. "Optimum design of linear tuned mass dampers for structures with nonlinear behaviour", Mechanical Systems and Signal Processing, 24, pp. 1739-1755 (2010). DOI: 10.1016/j.ymssp.2010.01.009

24. Arfiadi, Y. and Hadi, M.N.S. "Optimum placement and properties of tuned mass dampers using hybrid genetic algorithms", Iran University of Science \& Technology, 1, pp. 167-187 (2011).

25. Steinbuch, R. "Bionic optimisation of the earthquake resistance of high buildings by tuned mass dampers", Journal of Bionic Engineering, 8, pp. 335-344 (2011). DOI: $10.1016 / \mathrm{S} 1672-6529(11) 60036-\mathrm{X}$

26. Estekanchi, H.E. and Basim, M.C. "Optimal damper placement in steel frames by the endurance time method", The Structural Design of Tall and Special Buildings, 20, pp. $612-630$ (2011). DOI: $10.1002 /$ tal.689

27. Naderpour, H., Barros, R.C., Khatami, S.M., and Jankowski, R. "Numerical study on pounding between two adjacent buildings under earthquake excitation", Shock and Vibration, 2016, Article ID 1504783, 9 pages (2016). DOI: $10.1155 / 2016 / 1504783$

28. Naderpour, H. and Fakharian, P. "A synthesis of peak picking method and wavelet packet transform for structural equation: modal identification", KSCE Journal of Civil Engineering, 20, pp. 2859-2867 (2016). DOI: $10.1007 / \mathrm{s} 12205-016-0523-4$

29. Sakr, Tharwat A. "Vibration control of buildings by using partial floor loads as multiple tuned mass dampers", HBRC Journal, 13(2), pp. 133-144 (2017). DOI: $10.1016 /$ j.hbrcj.2015.04.004

\section{Biographies}

Hosein Naderpour received his $\mathrm{PhD}$ degree with high honors in Structural Engineering. He then joined Semnan University where he is presently an Associate
Professor of Structural Engineering. Since joining the Faculty of Civil Engineering at Semnan University, Dr. Naderpour has taught a variety of undergraduate and graduate courses in the areas of structural engineering, numerical methods, mechanics of materials, structural stability, concrete structures, structural reliability, as well as soft computing. Dr. Naderpour is the author of 60 papers published in journals and about 100 papers presented at national and international conferences. He has given several speeches in Switzerland, China, Australia, South Korea, Romania, Turkey, Canada, Hong Kong, Belgium, Portugal, Spain, Japan, Germany, Italy, Czech Republic, and France. He is currently a chief member of Iranian Earthquake Engineering Association, Iran Concrete Institute (ICI), Iranian Society for Light Steel Framing (LSF), Iran's National Elites Foundation, Safe School Committee, and Organization for Development, Renovation and Equipping Schools of Iran (DRES). Furthermore, he is currently the Editor-in-Chief of two international journals in the area of civil and mechanical engineering including Journal of Soft Computing in Civil Engineering (SCCE) and Journal of Computational Engineering and Physical Modeling (CEPM). His major research interests include the application of soft computing in structural engineering, seismic resilience, structural reliability, structural optimization, and damage detection of structures.

Arian Kiani was born in Tehran, Iran. He received his BS in the field of Civil Engineering in 2012, which was followed by successfully attaining his MS in Structural Engineering from Semnan University in 2015. His keen interests in research categories are soft computing in structural engineering, rehabilitation of structures, structural reliability, and control of structures. Currently, he is a $\mathrm{PhD}$ student of Structural Engineering at Semnan University, Semnan, Iran.

Ali Kheyroddin obtained his MS degree from Iran University of Science and Technology, Iran, and his $\mathrm{PhD}$ degree from McGill University, Canada. He is currently a Professor of Civil Engineering at Semnan University, Iran, and Chancellor of the University. He is the author of eight books, lots of ISI and ISC journal papers, and more than 200 conference papers. He has four patents. He has also supervised numerous $\mathrm{PhD}$ and MS degree theses. 